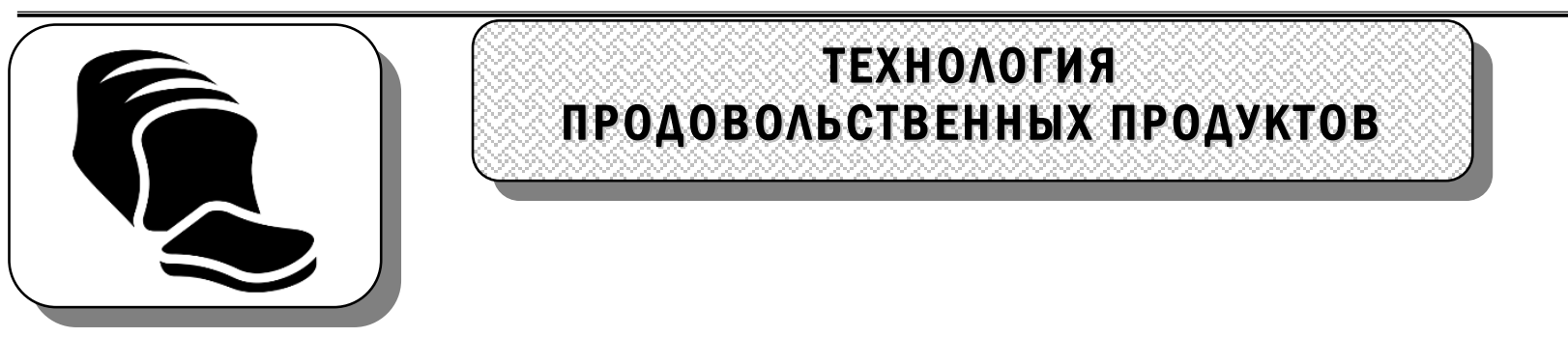

УДК 663.86.054.2

Н.А. Величко, Л.П. Шароглазова, Е.А. Рыгалова

DOI: $10.36718 / 1819-4036-2020-4-147-153$

\title{
РАЗРАБОТКА РЕЦЕПТУР БЕЗАЛКОГОЛЬНЫХ НАПИТКОВ С ИСПОЛЬЗОВАНИЕМ ПРОДУКТОВ ПЕРЕРАБОТКИ ДРЕВЕСНОЙ ЗЕЛЕНИ ХВОЙНЫХ
}

\section{N.A. Velichko, L.P. Sharoglazova, E.A. Rygalova

\begin{abstract}
THE DEVELOPMENT OF FORMULATIONS OF NON-ALCOHOLIC BEVERAGES USING THE PRODUCTS OF PROCESSING OF WOODEN GREENS OF THE CONIFERAE
\end{abstract}

\begin{abstract}
Величко Надежда Александровна - д-р техн. наук, проф., зав. каф. технологии консервирования и пищевой биотехнологии Красноярского государственного аграрного университета, г. Красноярск. E-mail: vena@kgau.ru
\end{abstract}

Шароглазова Лидия Петровна - канд. техн. наук, доц. каф. технологии консервирования и пищевой биотехнологии Красноярского государственного аграрного университета, г. Красноярск. E-mail: fppp@kgau.ru

Рыгалова Елизавета Александровна - канд. техн. наук, доц. каф. технологии консервирования и пищевой биотехнологии Красноярского государственного аграрного университета, г. Красноярск. E-mail: x3×3x@list.ru

B статье представлено 6 разработанных рещептур безалкогольных напитков с добавлением хвойного кедрового экстракта. Onределены органолептические показатели полученных напитков, на основании которых дозировка вносимого хвойного кедрового экстракта в различные рецептуры составила от 1 до 4 ке на 100 дал напитка. Установлены показатели безопасности разработанных напитков с кедровым хвойным экстрактом. Доказано, что разработанные безалкогольные газированные напитки с добавлением хвойного кедрового экстракта соответствуют нормативным показателям безопасности продукции. Предложена принципиальная схема их по-
Velichko Nadezhda Alexandrovna - Dr. Techn. Sci., Prof., Head, Chair of Technology of Canning and Food Biotechnology, Krasnoyarsk State Agrarian University, Krasnoyarsk.

E-mail: vena@kgau.ru

Sharoglazova Lidiya Petrovna - Cand. Techn. Sci., Assoc. Prof., Chair of Technology of Canning and Food Biotechnology, Krasnoyarsk State Agrarian University, Krasnoyarsk.

E-mail: fppp@kgau.ru

Rygalova Elizaveta Alexandrovna - Cand. Techn. Sci., Assoc. Prof., Chair of Technology of Canning and Food Biotechnology, Krasnoyarsk State Agrarian University, Krasnoyarsk, Krasnoyarsk.

E-mail: x3x3x@list.ru

лучения, включающая приготовление купажного cupona, в который входили сахарный сupon, хвойный кедровый экстракт, лимонная кислота, ароматизаторы, красители, экстракты (в зависимости от рецептуры), колер. Лимонную кислоту использовали в 50 \%-й концентрации, колер - в виде водного раствора в соотношении 1:5. Компоненты вносили в купаж в холодном состоянии при перемешивании в последовательности: сахарный сироп, хвойный кедровый экстракт, лимонная кислота, ароматизатор, краситель, экстракт (в зависимости от рецептуры), колер. Купажный cupon фильтровали, охлаждали до температуры 8$10{ }^{\circ} \mathrm{C}$, отправляли на розлив и смешивали с 
подготовленной газированной водой. Выбранный способ приготовления купажного сupona способствует получению более ароматных напитков.

Ключевые слова: рещептуры, безалкогольные напитки, хвойный кедровый экстракт, органолептические показатели, безопасность, технология.

Six developed recipes of soft drinks with the addition of coniferous cedar extract were presented in the study. Organoleptic parameters of obtained drinks were determined, on the basis of which the dosage of coniferous cedar extract introduced into various formulations ranged from 1 to $4 \mathrm{~kg}$ per 100 dal of the drink. Safety indicators of developed drinks with coniferous cedar extract were worked out. It was proved that the developed non-alcoholic carbonated drinks with the addition of coniferous cedar extract had met the regulatory indicators of product safety. The main diagram of their production, including the preparation of blended syrup, sugar syrup, coniferous cedar extract, citric acid, flavors, dyes, extracts (depending on the formulation), color was suggested. Citric acid was used in $50 \%$ concentration; the color was in the form of aqueous solution in the ratio of 1:5. The components were added to the blend in a cold state with stirring in the sequence: sugar syrup, coniferous cedar extract, citric acid, flavor, dye, extract (depending on the formulation) and color. The blended syrup was filtered, cooled to the temperature of 8$10^{\circ} \mathrm{C}$, sent for bottling and mixed with prepared carbonated water. The chosen method of preparation of blended syrup contributes to receiving more flavored drinks.

Keywords: formulations, soft drinks, coniferous cedar extract, organoleptic parameters, safety, technology.

Введение. К безалкогольным напиткам относятся напитки, не содержащие алкоголя (кола, пепси, газированная вода, чай, лимонад, пунш и т.д.). Чаще всего они представляют собой раствор сахара или сахарозаменителя, ароматизатора, красителя. Безалкогольные напитки пользуются большой популярностью у населения, особенно в летний период года.
В последнее время особое значение приобретают разработки, позволяющие получать на основе нетрадиционного сырья новые, оригинальные напитки, содержащие функционально значимые компоненты.

Безалкогольные напитки являются наиболее технологичной основой для создания продуктов, содержащих функциональные ингредиенты, так как введение в них новых компонентов не представляет большой сложности $[1,2]$.

Цель исследования. Разработка рецептур безалкогольных напитков с хвойным кедровым экстрактом и оценка качественных показателей и безопасности.

Задачи исследования: разработать рецептуры безалкогольных напитков с хвойным кедровым экстрактом; определить органолептические показатели напитков; установить показатели безопасности продукта.

Объекты и методы исследования. Для приготовления безалкогольных напитков использовали следующие компоненты:

- вода питьевая, соответствующая СанПиН 2.1.4.1074-01 и ГОСТ Р 51232-98, с жесткостью

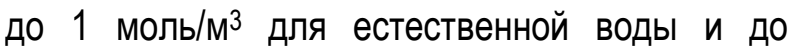
0,2 моль/м³ для исправленной воды;

- сахар-песок по ГОСТ 33222-2015;

- лимонная кислота - ГОСТ Р 53045-2008;

- красители;

- ароматизаторы.

Определение органолептических показателей проводили по ГОСТ6687.5-86 [3], токсичных элементов атомно-абсорбционным методом, показатели БГКП, КМАФАнМ, патогенные, в том числе сальмонеллы, - микробиологическим методом согласно требованиям ТР ТС 021/2011 «Технический регламент Таможенного союза "О безопасности пищевой продукции"» [4].

Результаты и их обсуждение. На основании предварительно проведенных экспериментальных исследований было подобрано количество добавляемого хвойного кедрового экстракта для каждой рецептуры, обеспечивающее наилучшие органолептические показатели напитка. Состав рецептур безалкогольных напитков с добавлением кедрового хвойного экстракта приведен в таблицах 1-6. 


\section{Состав рецептуры напитка «Шоколадный»}

\begin{tabular}{|c|c|c|}
\hline Компонент & Единица измерения & На 100 дал \\
\hline Caxap & КГ & 92,39 \\
\hline Лимонная кислота & Кг & 1,408 \\
\hline Экстракт кедровый & Кг & 4,00 \\
\hline Экстракт элеутерококка & л & 1,00 \\
\hline Краситель Е155 R240 «Шоколад» & КГ & 0,04 \\
\hline Вода & $\pi$ & 902,16 \\
\hline Итого & л & 1000 \\
\hline
\end{tabular}

\section{Состав рецептуры безалкогольного напитка «Абрикосовый»}

\begin{tabular}{|c|c|c|}
\hline Компонент & Единица измерения & На 100 дал \\
\hline Caxap & Кг & 92,39 \\
\hline Лимонная кислота & $\mathrm{K} \Gamma$ & 1,408 \\
\hline Экстракт кедровый & $\mathrm{K} \Gamma$ & 1,00 \\
\hline Ароматизатор «Абрикос» & $\pi$ & 0,4 \\
\hline Краситель сухой солнечный закат Е110 & Кг & 0,02 \\
\hline Краситель сухой тартразин Е102 & $\mathrm{K} \Gamma$ & 0,02 \\
\hline Вода & $\pi$ & 905,16 \\
\hline Итого & $\pi$ & 1000 \\
\hline
\end{tabular}

\section{Состав рецептуры напитка «Брусничный»}

\begin{tabular}{|c|c|c|}
\hline Компонент & Единица измерения & На 100 дал \\
\hline Caxap & $\mathrm{K} \Gamma$ & 92,39 \\
\hline Лимонная кислота & $\overline{\mathrm{K} \Gamma}$ & 1,408 \\
\hline Экстракт кедровый & КГ & 2,00 \\
\hline Краситель сухой спелая брусника R350 & КГ & 0,04 \\
\hline Вода & $\pi$ & 904,16 \\
\hline Итого & $\pi$ & 1000 \\
\hline
\end{tabular}

\section{Состав рецептуры напитка «Мятный»}

\begin{tabular}{|l|c|c|}
\hline \multicolumn{1}{|c|}{ Компонент } & Единица измерения & На 100 дал \\
\hline Сахар & кг & 92,39 \\
\hline Лимонная кислота & кг & 1,408 \\
\hline Экстракт кедровый & кг & 3,60 \\
\hline Краситель сухой синий блестящий Е133 & кг & 0,02 \\
\hline Краситель сухой тартразин Е102 & кг & 0,02 \\
\hline Ароматизатор «Мята» & $\pi$ & 0,4 \\
\hline Вода & $\pi$ & 902,56 \\
\hline Итого & $\pi$ & 1000 \\
\hline
\end{tabular}


Состав рецептуры напитка «Лимонный»

\begin{tabular}{|l|c|c|}
\hline \multicolumn{1}{|c|}{ Компонент } & Единица измерения & На 100 дал \\
\hline Сахар & кг & 92,39 \\
\hline Лимонная кислота & кг & 1,408 \\
\hline Экстракт кедровый & кг & 2,00 \\
\hline Краситель сухой солнечный закат Е110 & кг & 0,01 \\
\hline Краситель сухой тартразин Е102 & кг & 0,03 \\
\hline Ароматизатор «Лимон» & $л$ & 0,4 \\
\hline Вода & $л$ & 904,16 \\
\hline Итого & $л$ & 1000 \\
\hline
\end{tabular}

\section{Состав рецептуры напитка «Лайм»}

\begin{tabular}{|l|c|c|}
\hline \multicolumn{1}{|c|}{ Компонент } & Единица измерения & На 100 дал \\
\hline Сахар & кг & 92,39 \\
\hline Лимонная кислота & кг & 1,408 \\
\hline Экстракт кедровый & кг & 2,00 \\
\hline Краситель сухой синий блестящий Е133 & кг & 0,04 \\
\hline Ароматизатор «Лимон - лайм» & $л$ & 0,4 \\
\hline Вода & $л$ & 904,16 \\
\hline Итого & $л$ & 1000 \\
\hline
\end{tabular}

Органолептические показатели газированных напитков с хвойным кедровым экстрактом представлены в таблице 7.
Физико-химические показатели опытных образцов безалкогольных газированных напитков приведены в таблице 8.

Таблица 7

\section{Органолептические показатели безалкогольных газированных напитков}

\begin{tabular}{|c|c|c|c|}
\hline \multicolumn{1}{|c|}{ Напиток } & Внешний вид & Цвет & Вкус, аромат \\
\hline 1 & 2 & 3 & 4 \\
\hline Шоколадный & $\begin{array}{c}\text { Непрозрачная жидкость, } \\
\text { без посторонних включений }\end{array}$ & $\begin{array}{c}\text { Темно- } \\
\text { коричневый }\end{array}$ & $\begin{array}{c}\text { Вкус приятный, тонкий кедровый аро- } \\
\text { мат }\end{array}$ \\
\hline Абрикосовый & $\begin{array}{c}\text { Прозрачная жидкость, без } \\
\text { посторонних включений }\end{array}$ & $\begin{array}{c}\text { Желто- } \\
\text { оранжевый }\end{array}$ & $\begin{array}{c}\text { Абрикосовый вкус с легким кедровым } \\
\text { привкусом, с ярко выраженным абри- } \\
\text { косовым ароматом }\end{array}$ \\
\hline Брусничный & $\begin{array}{c}\text { Прозрачная жидкость, без } \\
\text { посторонних включений }\end{array}$ & $\begin{array}{c}\text { Темно- } \\
\text { красный }\end{array}$ & $\begin{array}{c}\text { Вкус и аромат приятные, со слегка } \\
\text { уловимыми нотками кедрового экс- } \\
\text { тракта }\end{array}$ \\
\hline Мятный & $\begin{array}{c}\text { Прозрачная жидкость, без } \\
\text { посторонних включений }\end{array}$ & Изумрудный & $\begin{array}{c}\text { Характерный мятный аромат, гармо- } \\
\text { ничный вкус с приятным послевкусием }\end{array}$ \\
\hline Лимонный & $\begin{array}{c}\text { Прозрачная жидкость, без } \\
\text { посторонних включений }\end{array}$ & $\begin{array}{c}\text { Желто- } \\
\text { оранжевый }\end{array}$ & $\begin{array}{c}\text { Ненавязчивый лимонный аромат, с } \\
\text { пикантным кедровым послевкусием }\end{array}$ \\
\hline Лайм & $\begin{array}{c}\text { Прозрачная жидкость, без } \\
\text { посторонних включений }\end{array}$ & Синий & $\begin{array}{c}\text { Слабый цитрусовый аромат, гармо- } \\
\text { ничный вкус с легким хвойным привку- } \\
\text { сом }\end{array}$ \\
\hline
\end{tabular}


Физико-химические показатели опытных образцов безалкогольных газированных напитков, \%

\begin{tabular}{|l|c|c|}
\hline \multirow{2}{*}{ Напиток } & \multicolumn{2}{|c|}{ Массовая доля } \\
\cline { 2 - 3 } & сухих веществ & двуокиси углерода \\
\hline Шоколадный & 9,5 & 0,3 \\
\hline Лимонный & 9,4 & 0,3 \\
\hline Мятный & 9,45 & 0,3 \\
\hline Брусничный & 9,4 & 0,3 \\
\hline Лайм & 9,4 & 0,3 \\
\hline Абрикосовый & 9,45 & 0,3 \\
\hline
\end{tabular}

Физико-химические показатели образцов безалкогольных напитков соответствуют ГОСТ P 28188-2014.

По микробиологическим показателям, по содержанию токсичных элементов и радионуклидов безалкогольные газированные и негазиро- ванные напитки должны отвечать требованиям, установленным ТР ТС 021/2011 «Технический регламент Таможенного союза "О безопасности пищевой продукции"». Показатели безопасности безалкогольных газированных напитков опытных образцов приведены в таблицах 9 и 10.

Таблица 9

\section{Содержание токсичных элементов в опытных безалкогольных напитках с Хвойным кедровым экстрактом, мг/кг}

\begin{tabular}{|l|c|c|}
\hline \multicolumn{1}{|c|}{ Элемент } & Норматив & Опыт \\
\hline Кадмий & Не более 0,03 & Менее 0,01 \\
\hline Медь & - & Менее 0,5 \\
\hline Свинец & Не более 0,3 & Менее 0,01 \\
\hline Цинк & - & Mенее 1,0 \\
\hline
\end{tabular}

Как следует из полученных результатов (табл. 9), содержание токсичных элементов во всех анализируемых безалкогольных газированных напитках с хвойным кедровым экстрактом не превышает нормативные показатели.
Результаты исследования на микробиологическую безопасность безалкогольных газированных напитков с добавлением хвойного кедрового экстракта представлены в таблице 10.

Таблица 10

Показатели микробиологической безопасности безалкогольных газированных напитков с хвойным кедровым экстрактом

\begin{tabular}{|l|c|c|}
\hline \multicolumn{1}{|c|}{ Показатель } & Норматив & Опыт \\
\hline БГКП (колиформы), см ${ }^{3}$ & В 333 не допускаются & В 333 не обнаружены \\
\hline КМФАнМ (КОЕ/ см $\left.{ }^{3}\right)$ & Не более 30 & Менее 1 \\
\hline Патогенные, в том числе сальмонеллы, г & В 100,0 не допускаются & В 100,0 не обнаружены \\
\hline
\end{tabular}

Из приведенных результатов (табл. 10) видно, что разработанные безалкогольные газированные напитки с хвойным кедровым экстрактом соответствуют нормативным показателям безопасности.
Согласно разработанным рецептурам безалкогольных напитков, предложена принципиальная схема их получения (рис.) 


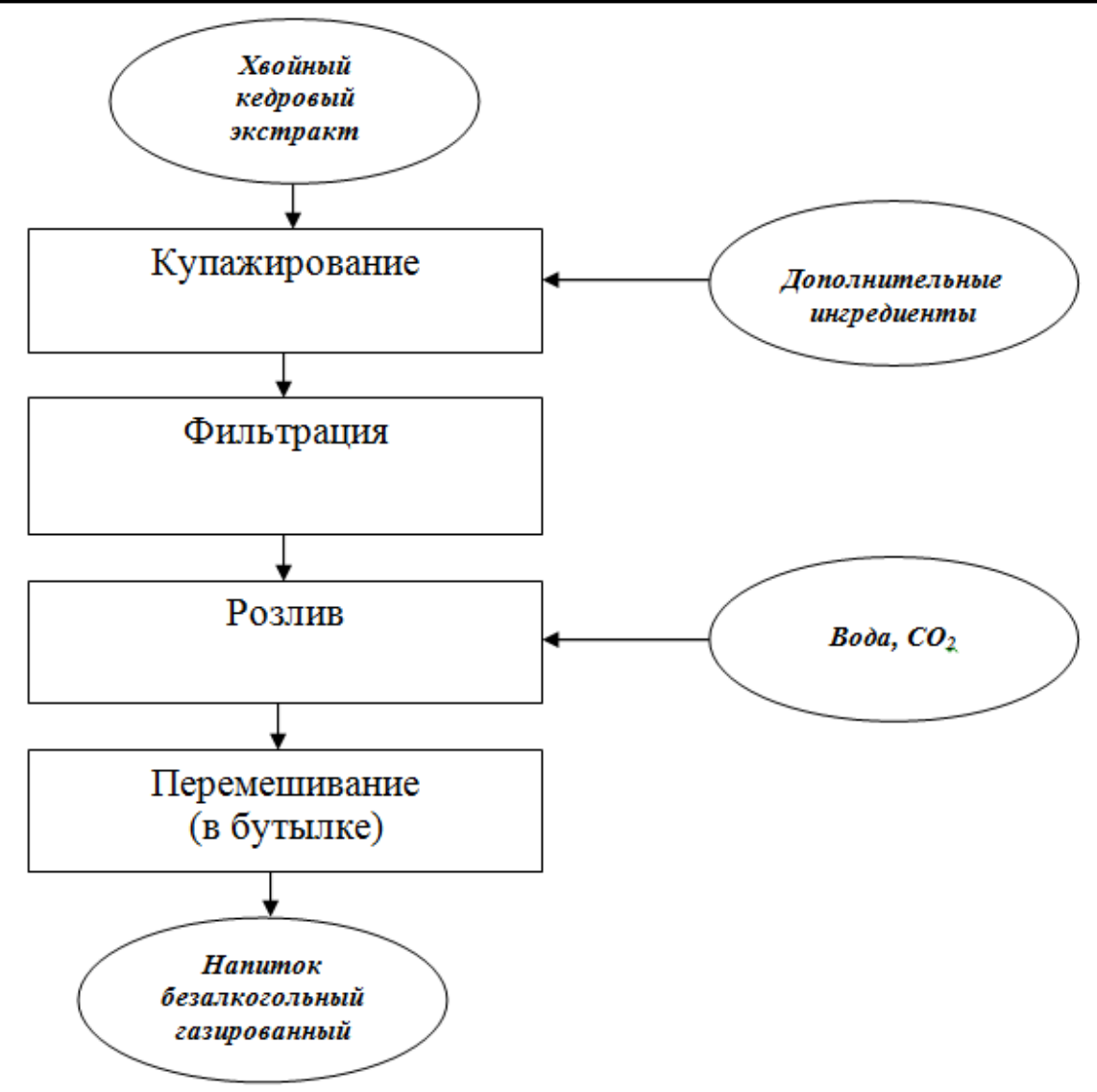

Принципиальная схема получения безалкогольного напитка с кедровым хвойным экстрактом

Начальным этапом производства газированного безалкогольного напитка с хвойным кедровым экстрактом было приготовление купажного сиропа, в который входили сахарный сироп, хвойный кедровый экстракт, лимонная кислота, ароматизаторы, красители, экстракты (в зависимости от рецептуры), колер.

Перед купажированием проводили подготовку ингредиентов. Лимонную кислоту использовали в 50\%-й концентрации. Колер - в виде водного раствора в соотношении 1:5. Сахарпесок просеивали через сито и отправляли на варку сахарного сиропа.

Купажный сироп готовили холодным способом. Компоненты вносили в купаж в холодном состоянии при перемешивании в последовательности: сахарный сироп, хвойный кедровый экстракт, лимонная кислота, ароматизатор, краситель, экстракт (в зависимости от рецептуры), колер.

Выбранный способ приготовления купажного сиропа обусловлен вкусовыми качествами выпускаемого продукта, напитки получаются более ароматными.
С целью получения прозрачного купажного сиропа его подвергали фильтрации, после чего охлаждали до температуры 8-10 ${ }^{\circ} \mathrm{C}$, отправляли на розлив и смешивали с подготовленной газированной водой.

Подготовленную воду перед сатурацией охлаждали до температуры $1-2{ }^{\circ} \mathrm{C}$, так как растворимость углекислого газа в воде с понижением температуры воды увеличивается, затем проводили деаэрирование с помощью вакуума и отправляли на сатуратор. Содержание $\mathrm{CO}_{2}$ в воде на выходе из сатуратора должно быть не менее $0,66 \%$ к массе.

Рассчитанную дозу купажного сиропа наливали в чисто вымытые бутылки. Во избежание потерь диоксида углерода, растворенного в газированных безалкогольных напитках, наполнение бутылок проводится под избыточным давлением. Температура газированной воды при наливе в бутылку не должна превышать $4{ }^{\circ} \mathrm{C}$, а температура готового напитка не выше $8^{\circ} \mathrm{C}$.

Для снижения потерь диоксида углерода наполненные бутылки сразу укупоривают. Укупоренные бутылки тщательно перемешивают. 
Бутылки с готовым напитком после укупорки и перемешивания подвергают тщательному просмотру перед световым экраном, переворачивая их вверх дном. Бутылки, налитые не полно либо недостаточно плотно укупоренные или с содержанием каких-то примесей, выбраковывают. После проверки на бутылки наклеивают соответствующие этикетки.

Выводы. Разработано 6 рецептур безалкогольных напитков с добавлением хвойного кедрового экстракта. Определены органолептические показатели полученных напитков, на основании которых дозировка вносимого хвойного кедрового экстракта составила от 1 до 4 кг на 100 дал напитка. Установлены фризикохимические и показатели безопасности разработанных напитков с кедровым хвойным экстрактом. Доказано, что разработанные безалкогольные газированные напитки с хвойным кедровым экстрактом соответствуют нормативным показателям безопасности. Предложена принципиальная схема их получения.

\section{Литература}

1. Шароглазова Л.П., Величко Н.А. Разработка рецептуры безалкогольного напитка $\mathrm{C}$ использованием ягод морошки // Вестник КрасГАУ. 2016. № 2. С. 88-92.

2. Рьгалова Е.А., Величко Н.А. Исследование потребительского спроса фуннкциональных напитков // Наука и образование: опыт, проблемы, перспективы развития: мат-лы междунар. науч.-практ. конф. Ч. II. Красноярск, 2018. С. 144-148.

3. ГОСТ 6687.5-86. Продукция безалкогольной промышленности. Методы определения органолептических показателей и объема продукции. М.: Стандартинформ, 2009. 11 с.

4. TP ТС 021/2011. Технический регламент Таможенного союза «О безопасности и пищевой продукции» // СПС «Консультантплюс».

\section{Literatura}

1. Sharoglazova L.P., Velichko N.A. Razrabotka receptury bezalkogol'nogo napitka $\mathrm{s}$ ispol'zovaniem jagod moroshki // Vestnik KrasGAU. 2016. № 2. S. 88-92.

2. Rygalova E.A., Velichko N.A. Issledovanie potrebitel'skogo sprosa funkcional'nyh napitkov /I Nauka i obrazovanie: opyt, problemy, perspektivy razvitija: mat-ly mezhdunar. nauch.-prakt. konf. Ch. II. Krasnojarsk, 2018. S. 144-148.

3. GOST 6687.5-86. Produkcija bezalkogol'noj promyshlennosti. Metody opredelenija organolepticheskih pokazatelej i ob'ema produkcii. M.: Standartlnform, 2009. $11 \mathrm{~s}$.

4. TR TS 021/2011. Tehnicheskij reglament Tamozhennogo sojuza «O bezopasnosti i pishhevoj produkcii» // SPS «Konsultantpljus». 